\title{
Potansiyel Bir Adsorban Olarak Perlit İçeren Polisakkarit Esaslı Küresel Hibrit Tanecikler
}

\author{
İlknur Küçük ${ }^{1 *}$, İrem Sarısakal ${ }^{2}$ \\ ${ }^{1 *}$ Yıldız Teknik Üniversitesi, Kimya Metalurji Fakültesi, Kimya Mühendisliği Bölümü, İstanbul, Türkiye (ORCID: 0000-0001-9203-0693), kucuk@yildiz.edu.tr \\ ${ }^{2}$ Yıldız Teknik Üniversitesi, Kimya Metalurji Fakültesi, Kimya Mühendisliği Bölümü, İstanbul, Türkiye (ORCID: 0000-0003-2826-1053), cicekirem@gmail.com
}

(Illk Geliş Tarihi 28 Temmuz 2020 ve Kabul Tarihi 10 Ekim 2020)

(DOI: $10.31590 /$ ejosat.774982)

ATIF/REFERENCE: Küçük, İ. \& Sarısakal, İ. (2020). Potansiyel Bir Adsorban Olarak Perlit İçeren Polisakkarit Esaslı Küresel Hibrit Tanecikler. Avrupa Bilim ve Teknoloji Dergisi, (20), 216-222.

\section{$\ddot{O} \mathbf{z}$}

Bu çalışmada, potansiyel bir adsorban olarak kullanılabilecek, sodyum aljinat esaslı, perlit içeren küresel hibrit tanecikler ani jelleşme

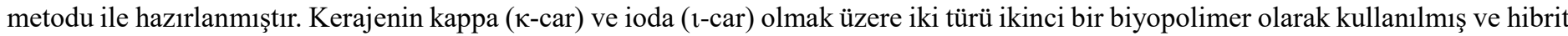
taneciklerin fonksiyonel gruplarını çeşitlendirilmiştir. Pek çok uygulama için çok önemli bir faktör olan tanecik boyutu ve kararlılığına aljinatın molekül ağırlığının, jel çözelti konsantrasyonunun, kerajen ve perlit oranının etkisi incelenmiştir. Hazırlanan hibrit taneciklerin şekil, çap ve şişme dereceleri belirlenerek fiziksel, Fourier Transform lnfrared (FTIR) spektroskopi kullanılarak yapısal ve taramalı elektron mikroskobu (SEM) kullanılarak morfolojik karakterizasyonu yapılmıştır. Yüksek molekül ağırlıklı ve \%2 (w/v) lik sodyum aljinat ile hazırlanan hibrit taneciklerin küresel şekil kararlılığını koruduğu, kerajenin her iki türünün \%20 (ağ.)'ye kadar yapıya girmesinin küreselliği bozmadığı, \%20 (ağ.) oranına kadar katılan perlitin ise taneciklerin kuru halde küreselliklerini kaybetmelerine neden olduğu görülmüştür. Hazırlanan hibrit tanecikler ile ağır metal olarak seçilen bakırın sulu çözeltilerinden giderim etkinliği araştırılmış ve perlit içeren hibrit taneciklerin 10 ppm başlangıç konsantrasyonunda bakırı \%77,1 oranında giderebildiği görülmüştür.

\section{Spherical Hybrid Beads Based on Polysaccharide incorpareted with Pearlite as a Potential Adsorbent}

\begin{abstract}
In this study, spherical hybrid beads based on polysaccharides incorporated with pearlite, which can be a potential adsorbent, were prepared by using instant gelation methods. Kappa ( $\kappa$-car) and ioda ( 1 -car) carrageenan were used as a second biopolymer to vary the functional groups of hybrid beads. Particle size and its stability is a very important factor for many applications. The effect of the molecular weight and concentration of the alginate, the ratio of keragen and perlite, to the particle size of hybrid beads and stability were investigated. Hybrid beads have been characterized by physical properties such as appearance, diameter and swelling degree as their structures and morphology were confirmed by Fourier Transform lnfrared Spectroscopy (FTIR) and Scanning Electron Microscope (SEM). It was observed that hybrid beads that were prepared by using high molecular weight alginate and its $2 \%$,(w/v) gel solution retains its spherical shape. It was observed that both types of carrageenan ratio in the hybrid beads structure up to $20 \%$ (wt) at the $2 \%$ (wt) constant jel concentration were not deformed spherical shape of beads while pearlite caused lose their spherical shape at the dry state. Heavy metal removal efficiency of hybrid gel beads was investigated for aqueous copper solution and was found to be $77.1 \%$ for hybrid beads incorporated pearlite $(10 \%, \mathrm{wt})$ at the $10 \mathrm{ppm}$ initial concentration of the copper solution.
\end{abstract}

Keywords: Hybrid beads, Polysaccharide, Pearlite, Heavy metal.

\footnotetext{
*Sorumlu Yazar: kucuk@yildiz.edu.tr
} 


\section{Giriş}

İnsan sağlığı ve ekolojik sistem için tehdit oluşturan kirlilikler en önemli çevre sorunlarının başında gelmektedir. $\mathrm{Bu}$ sorunun çözümüne ve kullanılan teknikleri geliştirilmesine yönelik çalışmalar hiç hız kaybetmezken sulu çözeltilerden ağır metal gideriminde kimyasal çöktürme (Balladeres ve ark., 2018), filtrasyon (Bessbousse ve ark., 2008), iyon değişimi (İbrahim ve ark., 2020), membran teknolojileri (Klaassen ve ark., 2005), adsorpsiyon (Renu ve ark., 2017) gibi çok çeşitli teknikler kullanılmaktadır. Ağır metal gideriminde önemli bir yer tutan adsorpsiyon yönteminde ise kullanılan adsorban kilit rol oynamaktadır (Saleh ve ark., 2019; Wang ve Chen, 2009).

Çok farklı kaynaklardan elde edilebilen doğal polisakkaritlerin, kolay bulunmaları, biyouyumlulukları (Fouda ve ark., 2015), toksik olmamaları (Keppeler ve ark., 2009), düşük maliyetleri gibi özellikleri onların son yıllarda pek çok alanda tercih edilen malzemelerin başında gelmelerini sağlamaktadır (Dias ve ark., 2011; Yang ve ark., 2015). Hidroksil, karboksil ve amino grupları başta olmak üzere ana zincirleri üzerindeki çok çeşitli fonksiyonel gruplar, polisakkaritlerin kolaylıkla kimyasal ve biyokimyasal olarak modifiye edilebilmesine olanak tanırken (Yang ve ark., 2015); aynı zamanda bu fonksiyonel gruplar gida, ilaç, doku mühendisliği, biyomedikal uygulamalar, plastik, su arıtımı gibi birçok alanda tanecik (Yang ve ark., 2015; Gotoh ve ark., 2004), film (Campo, 2009), kapsül (Rinaudo, 2008) gibi farklı şekillerde kullanılabilmektedir. İçeriğindeki karboksil gruplarıyla amino gruplarının eşleşip hibrit yapı oluşturmasıyla mikroküre ya da nano partiküller halinde tanecikler elde edilmektedir (Gotoh ve ark., 2004).

Alginatın ani jel yöntemiyle (Li ve ark., 2007; Lee and Mooney, 2012) kolaylıkla çapraz bağlanarak küresel tanecikler şeklinde elde edilebilmesi ve kerajenin de bu çapraz bağlı yap1 içerisinde hapsedilebilmesi polisakkaritlere önemli avantajlar kazandırmaktadır (Yu ve ark., 2019). Alginat ve kerajen ile hibrit yapıda küresel tanecikler şeklinde elde edilebilmekle birlikte yapıya katılarak hem bu taneciklerin mekanik dayanımına hem de adsorpiyon kabiliyetine pozitif yönde katkı sağlayabilecek inorganik bileşenlerin araştırılmasına yönelik çalışmalar da önem kazanmıştır (Zang ve ark., 2010).

Perlit ucuz, bol miktarda bulunan; hafif, kimyasal pasifliği bulunan; çevre dostu bir malzemedir (Roulia ve ark., 2003). Ayrıca perlitin gözenekli yapısı hem başına iyi bir adsorban olarak hem de kompozit yap1 katılarak kullanılabilmesine olanak tanımaktadır (Roulia ve Vassiliadis, 2008).

$\mathrm{Bu}$ çalışmada, içeriğinde karbonil, sülfonil ve hidroksil fonksiyonel gruplarını barındıran alginat ve kerajen biyopolimerleri esas alınarak oluşturulan matris yapıya, ucuz, kolayca elde edilebilen ve bulunduğu yapının mekanik dayanımını arttırabilen perlit eklenerek hem fonksiyonel gruplarını hem de küreselliği muhafaza edilen hibrit yapıda potansiyel bir adsorbanının hazırlanması hedeflenmiştir. Küresel olarak hazırlanabilen bu hibrit taneciklerin fiziksel ve yapısal özellikleri karakterize edilmiş ve ağır metal olarak seçilen bakırı çeşitli başlangıç konsantarasyonlarındaki sulu çözeltilerinden ne oranda giderebileceği araştırılmıştır.

\section{Materyal ve Metot}

\subsection{Jel Çözelti Konsantrasyonunun Belirlenmesi ve Küresel Taneciklerin Hazırlanması}

Sodyum aljinat (NaAlg) (yüksek ve düşük molekül ağırlıklarında) ve kalsiyum klorür, bakır stok çözeltisi, Sigma Aldrich'ten, kerajen (ioda ve kappa) Moleculer Recipe, WillPowder'dan ve perlit, Taşper Perlit San. Tic.Ltd.Şti'den temin edilmiş ve herhangi bir ön işleme tabi tutulmadan kullanılmışlardır.

Sodyum aljinat biyopolimerinin molekül ağırlığının ve çözeltideki konsantrasyonunun kombinasyonu, elastikiyetin ve dolayısıyla nihai ürünün şeklinin belirlenmesinde kritik öneme sahiptir. Şekil kararlılığını koruyabilen küresel tanecik eldesinde molekül ağırlığı ve konsantrasyon etkisi belirlemek için öncelikle düşük molekül ağırlıklı (DMA) ve yüksek molekül ağırlıklı (YMA) sodyum aljinat kullanılarak toplam jel konsantrasyonu ağırlıkça \%1,5, \%2 ve $\% 3$ olmak üzere jel çözeltileri hazırlanmıştır. Düşük molekül ağırlıklı sodyum alginat ile $\% 1,5$ jel konsantrasyonunda tanecik elde edilemediği, $\% 2$ jel konsantrasyonunda hazırlanan taneciklerin ise sslak ve kuru iken hem küresellikten uzak hem de şekil kararlılığını koruyamadığı görülmüştür. \%3 jel konsantrasyonu ile hazırlanan taneciklerinin 1slakken daha küresele yakın, ancak kuruduğunda ise yine şekil kararlılığını koruyamadığı görülmüştür (Şekil 1). Yüksek molekül ağırlıklı sodyum aljinat kullanılarak toplam jel konsantrasyonu Şekil 2'de \%1,5, \%2 ve \%3 olmak üzere hazırlanan taneciklerin sslak ve kuru halleri görülmektedir. $\% 2$ ve $\% 3$ jel konsantrasyonlarında hazırlanan taneciklerin, $\% 1,5$ jel konsantrasyonuna göre çok daha iyi küresellik gösterdiği, ,slak ve kuru haldeyken şekil kararlılığını koruduğu görülmüştür. \%2 ve $\% 3$ jel konsantrasyonunda hazırlanan taneciklerin benzer küresellikte olmaları dolayısı ile sonraki çalışmalara YMA sodyum aljinat ve toplam jel konsantrasyonu \%2 esas alınarak devam edilmiştir.

Jel çözeltilerinin hazırlanmasında kullanılan tipik bir yöntem şöyle verilebilir: \%2 lik sodyum aljinat jel çözeltisi, beher içerisinde tartılan $2 \mathrm{~g}$ sodyum aljınat üzerine $100 \mathrm{ml}$ distile su eklenerek 24 saat boyunca oda sıcaklığında manyetik karıştırıcıda karıştırılarak hazırlanmıştır. \%1,5 lik kerajen çözeltileri ise; 1,5 g kerajen üzerine $100 \mathrm{ml}$ distile su eklenerek, 1 saat boyunca 80 ${ }^{\circ} \mathrm{C}$ 'de manyetik karıştırıcıda karıştırılmış daha sonra sıcaklık $35^{\circ} \mathrm{C}$ 'ye düşürülerek 1 saat daha karıştırma işlemine devam edilmiş ve kerajenin homojenliği sağlanmıştır. Aljinat ve karajen jel karışımları her iki jel çözeltisinin belirlenen oranları için oda sıcaklığında 1 saat boyunca manyetik karıştırıcıda karıştırılması ile hazırlanırken, perlit içeren jeller ise toz perlitin belirlenen oranda jel çözeltilerine eklenerek, oda sıcaklığında 1 saat boyunca manyetik karıştırıcıda karıştırılarak elde edilmiştir.

Küresel taneciklerin hazırlanmasında ani jel yöntemi kullanılmıştır. Jel çözeltisi saf su ile kalibre edilmiş ucuna $5 \mathrm{~cm}$ uzunluğunda $0,4 \mathrm{~mm}$ çapında nozul takılı peristaltik pompa (Masterflex L/S) ile $500 \mathrm{~mL} 2 \mathrm{M} \mathrm{CaCl} 2$ içeren çözeltiye damlatılmış ve 24 saat bekletilerek çapraz bağlanmaları sağlanmıştır, daha sonra saf su ile yıkanan tanecikler ve oda sıcaklığında kurutulmuştur. Çalışmada kullanılan ve hazırlanan hibrit taneciklerin bileşimleri ve kodları Tablo 1'de görülmektedir. 

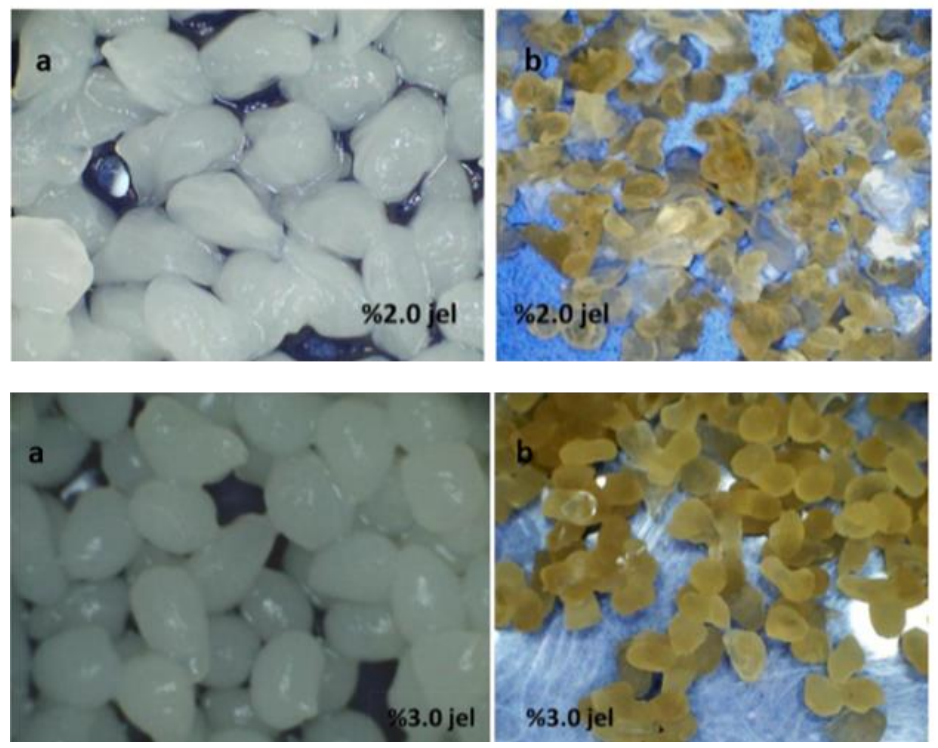

Şekil 1. \%2 ve \%3 Jel Konsantrasyonlarında Hazırlanan DMA-NaAlg Tanecikleri (a:ıslak, b:kuru)
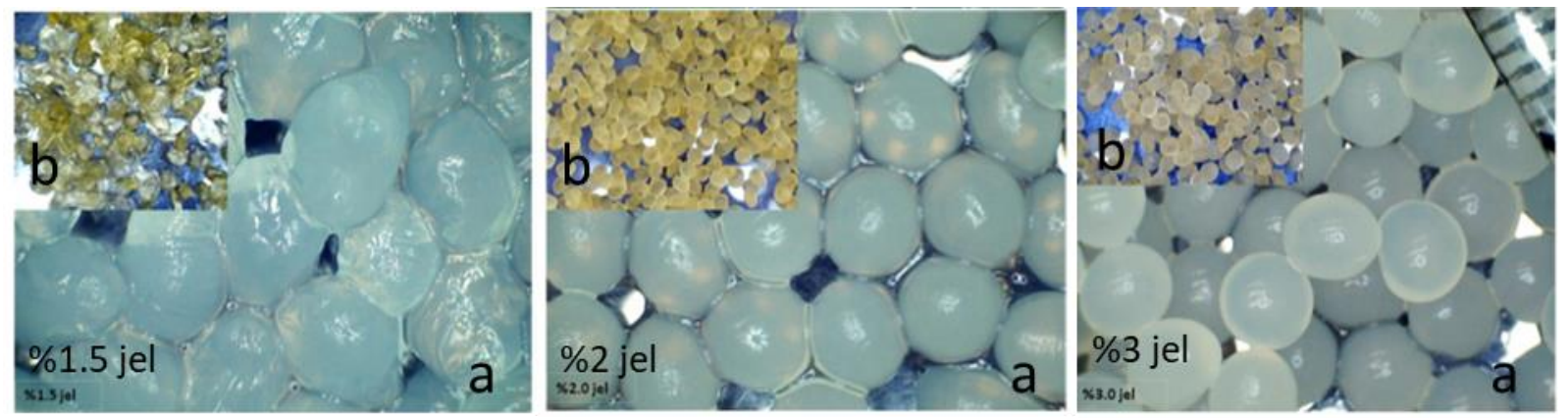

Şekil 2. \%1,5, \%2 ve \%3 Jel Konsantrasyonlarında Hazırlanan YMA-NaAlg Tanecikleri (a:ıslak, b:kuru)

Tablo 1. Çalış̧mada Hazırlanan Hibrit Tanecikler

\begin{tabular}{|c|c|c|c|}
\hline Bileşenler & Kodlama & Oran & \multirow{10}{*}{$\begin{array}{c}\text { Çözeltinin Toplam } \\
\text { Jel Konsantrasyonu } \\
\% 2(\mathrm{w} / \mathrm{v})\end{array}$} \\
\hline \multirow{3}{*}{$\mathrm{NaAlg} /(\kappa-\mathrm{car})$} & AK10 & $90: 10$ & \\
\hline & AK20 & $80: 20$ & \\
\hline & AK30 & $70: 30$ & \\
\hline \multirow{3}{*}{$\mathrm{NaAlg} /(1-\mathrm{car})$} & AI10 & $90: 10$ & \\
\hline & AI20 & $80: 20$ & \\
\hline & AI30 & $70: 30$ & \\
\hline \multirow{3}{*}{ NaAlg/Perlit } & AP10 & $90: 10$ & \\
\hline & AP20 & $80: 20$ & \\
\hline & AP30 & $70: 30$ & \\
\hline
\end{tabular}

\subsubsection{Karakterizasyon}

Elde edilen tanecikler küresellik, çap ve şişme dereceleri belirlenerek fiziksel olarak karakterize edilmiştir. Islak ve kuru taneciklerin küresellikleri Veho VMS004 markalı dijital bir kamera ile görüntülenmiş; çapları ImageJ programı ile belirlenmiștir. Șişme derecesini belirlemek için tanecikler 25 ${ }^{\circ} \mathrm{C}$ 'de sabit ağırlığa kurutularak başlangıç kuru ağırlıkları $\left(\mathrm{W}_{\mathrm{i}}\right)$ belirlenmiştir. Daha sonra, 24 saat boyunca deiyonize suya daldırılan ve sabit tartıma ulaşan tanecikler sudan çıkarılmış, bir kağıt dokusu kullanılarak tanecik yüzeyi üzerindeki fazla su morfolojik karakterizasyon için JEOL marka JSM6335F model Taramalı Elektron Mikroskobu (SEM) kullanılmıştır. uzaklaştırılmış ve nihai ağırlıkları belirlenmiştir $\left(\mathrm{W}_{\mathrm{f}}\right)$. Taneciklerin şişme derecesi (SD) aşağıda verilen denklem (1) kullanılarak hesaplanmışıır:

$$
S D \%=\frac{W_{f}-W_{i}}{W_{i}} \times 100
$$

Hazırlanan taneciklerin yapısal karakterizasyonları; FTIR spektrumu (4000-400 $\left.\mathrm{cm}^{-1}\right)$ bölgesinde ve $4 \mathrm{~cm}^{-1}$ çözünürlükte Perkin Elmer Spectrum One Bruker Marka Tensor 27 Model Platinum FTIR (ATR) spektrometresi kullanılarak yapılırken

Hibrit taneciklerin ne oranda bakır giderebildiğini belirleyebilmek için 10,30 ve 50 ppm olmak üzere üç farklı başlangıç konsantrasyonunda bakır çözeltisi hazırlanmıştır. 100 
$\mathrm{mL}$ lik çözelti için 0,5 g hibrit tanecik orbital çalkalayıcıda 190 devir/dakika denge konsantrasyonuna ulaşılana kadar karıştırılmıştır ve bir atomik Absorbsiyon Spektrofotometresi (Analytik Jena Nova 300) ile çözelti konsantrasyonları belirlenmiştir. Adsorbe edilen bakır iyonlarının miktarı aşağıda verilen denklem (2) ile hesaplanmıştır:

$$
Q_{e}=\frac{\left(C_{0}-C\right) * V}{m}
$$

Burada; $\mathrm{Q}_{\mathrm{e}}$ : bakır tutma kapasitesi (mg Cu/g adsorban), $\mathrm{C}_{\mathrm{o}}$ : başlangıç konsantrasyon (ppm), C: denge konsantrasyonu (ppm), $\mathrm{V}$ : çözelti hacmi (mL), m: eklenen adsorban miktarı (g) dir. Hibrit taneciklerin \% bakır giderimi ise aşağıdaki şekilde hesaplanmıştır.

$$
\% \text { Giderim }=\frac{\text { Adsorplanan Bakır miktarı }}{\text { Başlangıç çözelti konsantrasyonu }} \times 100
$$

\section{Araştırma Sonuçları ve Tartışma}

Sodyum alginatın molekül ağırlığının ve jel çözelitisi konsantrasyonunun ile tanecik özelliklerini etkilediği, molekül ağırlığının artmasının taneciklerin mekanik özelliklerini iyileştirdiği ve elde edilen taneciklerin kararlı bir yapı gösterdiği bilinmektedir (Caballero ve ark., 2014; Lee ve Mooney, 2012).

Kappa kerajen ( $\kappa$-car), ioda kerajen ( 1 -car) ve Perlit içeren hibrit taneciklerin sslak ve kuru çapları ve şişme dereceleri Tablo 2'de verilmiştir. Hibrit taneciklerin çaplarının 4,3 $\mathrm{mm}$ ile 7,4 mm ve kuruduklarında ise $1,2 \mathrm{~mm}$ ile $1,7 \mathrm{~mm}$ arasında değiştiğ görülmektedir. Hibrit yap1 içerisinde hem $\kappa$-car hem de 1 -car oranının artmasının hem taneciğin çapını hemde şişme derecesini artırdığı açık olarak görülmektedir. Bu durum özellikle kerajenin her iki türününde sahip olduğu fonksiyonel grupların su ile etkileşmesi ile etkileşmesinin sonucudur (Cabellero ve ark., 2014). Su ile etkileşebilen fonksiyonel gruplarının olmaması dolayısı ile yapı içerisndeki perlitin oranın artması hibrit taneciklerin çap ve şişme derecesini etkilememiştir.

\begin{tabular}{|c|c|c|c|}
\hline Örnek & $\begin{array}{r}\text { Islak } \\
\text { çap (mm) }\end{array}$ & $\begin{array}{r}\text { Kuru } \\
\text { Çap (mm) } \\
\end{array}$ & $(\%)^{\text {SD }}$ \\
\hline AK10 & 5,211 & 1,242 & 54,05 \\
\hline AK20 & 6,464 & 1,623 & 65,11 \\
\hline AK30 & 7,451 & 1,715 & 75,82 \\
\hline AI10 & 4,064 & 1,718 & 44,22 \\
\hline AI20 & 4,770 & 1,612 & 46,67 \\
\hline AI30 & 4,715 & 1,150 & 47,37 \\
\hline AP10 & 4,544 & 1,477 & 33,11 \\
\hline AP20 & 4,427 & 1,507 & 31,28 \\
\hline AP30 & 4,331 & 1,712 & 32,15 \\
\hline
\end{tabular}

Tablo 2. Hibrit Taneciklerin Çapları ve Şişme Dereceleri

Kappa kerajen ( $\kappa$-car), ioda kerajen ( 1 -car) ve Perlit içeren taneciklerin 1slak ve kuru görünümleri Şekil 3'de görülmektedir.
AK10, AI10 ve AP10 hibrit taneciklerinin hem 1slak hem de kuru halde küreselliklerini korudukları görülmektedir. Bununla birlikte, yapı içerisinde her iki tür kerajen ve perlit için konsantrasyonunun artması taneciklerinin kururken şekil kararlılığını korumasını zorlaştırmaktadır. Kerajen içeren tanecikler için bu durum kerajenin fonksiyonel gruplarının su tutma kapasitesini arttırması ve taneciğin su ile şişmesinin küreselliğine sebep olması; suyun buharlaşması ile de kuruyan taneciğin şeklini kaybetmesine neden olması ile açıklanabilir (Caballero ve ark., 2014). -car içeren taneciklerinin, 1slakken $\kappa$ car içeren taneciklerine kıyasla daha az küresel olduğu; ancak kuruduğunda küresel şekillerini koruyabildikleri görülmüştür. Kerajen türünün hibrit taneciklerin şekil kararlılığı üzerinde çok fazla etkisi olmadığ

AP10, AP20 ve AP30 taneciklerinin 1slak haldeyken küresel, kuruduğunda ise küresellikten uzaklaştığ 1 görülmüştür. Perlitin kayaç yapısı sebebiyle kuruduğunda küreselliğinin azalması beklenen bir sonuçtur (Sarısakal, 2017). Perlit içeren tanecikleri SEM görüntüleri (Şekil 4) de kayaç yapısını doğrulamaktadır.

Hibrit taneciklerin FT-IR spekturumları Sekil 4'de gösterilmiştir. NaAlg spesifik pikleri absorbsiyon bandında 3256 $\mathrm{cm}^{-1}$ de hidroksil gruplarının piklerini, 1591 ve $1407 \mathrm{~cm}^{-1}$ bandlarında ise sirasıyla - $\mathrm{COO}$ asimetrik ve - $\mathrm{COO}$ simetrik bağlarının piklerini, $1025 \mathrm{~cm}^{-1}$ ' de ise C-O-C grubuna ait pikin yer aldığını görülmektedir. Kappa kerajenin karasteristik sülfon grubu $(\mathrm{O}=\mathrm{S}=\mathrm{O}) 1219 \mathrm{~cm}^{-1}$ de, $\mathrm{C}-\mathrm{O}-\mathrm{C}$ bağına ait pik $1033 \mathrm{~cm}^{-1}$ 'de, C-O bağına ait pik $924 \mathrm{~cm}^{-1}$ 'de ve C-O-S ait pik ise $844 \mathrm{~cm}^{-}$ ${ }^{1}$ de görülmektedir. AK20 hibrit taneciğinde $1216 \mathrm{~cm}^{-1}$ da görülen $\mathrm{O}=\mathrm{S}=\mathrm{O}$ grubuna ait pik yapı içerisindeki $\kappa$-car varlığını doğrulamaktadır. Benzer şekilde ioda kerajenin $1280 \mathrm{~cm}^{-1}$ de bulunan karasteriktik sülfon grubunun $(\mathrm{O}=\mathrm{S}=\mathrm{O}), 1256 \mathrm{~cm}^{-1} \mathrm{de}$ AI20 hibrit taneciğinin yapısında yer aldığ 1 görülmektedir. AP20 taneciklerinin FTIR spektrumunda, alginattan gelen -COO asimetrik piki $1589 \mathrm{~cm}^{-1}$ de, -COO simetrik piki $1367 \mathrm{~cm}^{-1}$ de görülürken C-O-C bağına ait pik $1024 \mathrm{~cm}^{-1}$ 'de, Si-O-Si simetrik piki $902 \mathrm{~cm}^{-1}$ 'de görülmüştür. Perlitin $1035 \mathrm{~cm}^{-1}$ 'deki Si-O-Si asimetrik pikinin, alginatta hemen hemen aynı hizada yer alan $1025 \mathrm{~cm}^{-1}$ 'deki C-O-C bağ1 ile çakıştığ 1 ve üzerini kapattığ kanısına varılmıştır. AP20 hibrit taneciğine ait SEM görüntüsü yapı içerisindeki perlitin varlığını açıkça ortaya koymaktadır.

Hibrit taneciklerin potansiye adsorban olarak kullanılabilirliğini araştırmak amacıyla AK10, AI10 ve AP10 tanecikleri seçilerek; $10 \mathrm{ppm}, 30 \mathrm{ppm}$ ve $50 \mathrm{ppm}$ başlangıç konsantrasyonlarındaki bakır giderme yüzdeleri incelenmiştir (Şekil 5).

Her üç tanecik içinde en yüksek giderimin başlangıç konsantrasyonu $10 \mathrm{ppm}$ de gerçekleşirken bu konsantrasyonda AP10 taneciklerinin \%77,1, AI10 taneciklerinin \%74,05 ve AK10 taneciklerinin $\% 67,1$ oranında bakırı giderebildiği görülmüştür. Başlangıç konsantrasyonunun artması ile tüm taneciklerin bakır giderim verimliliğinin azaldığı ve yüksek başlangıç konsantrasyonunda tanecik yapısının giderim verimliliğini etkilemediği görülmektedir. 

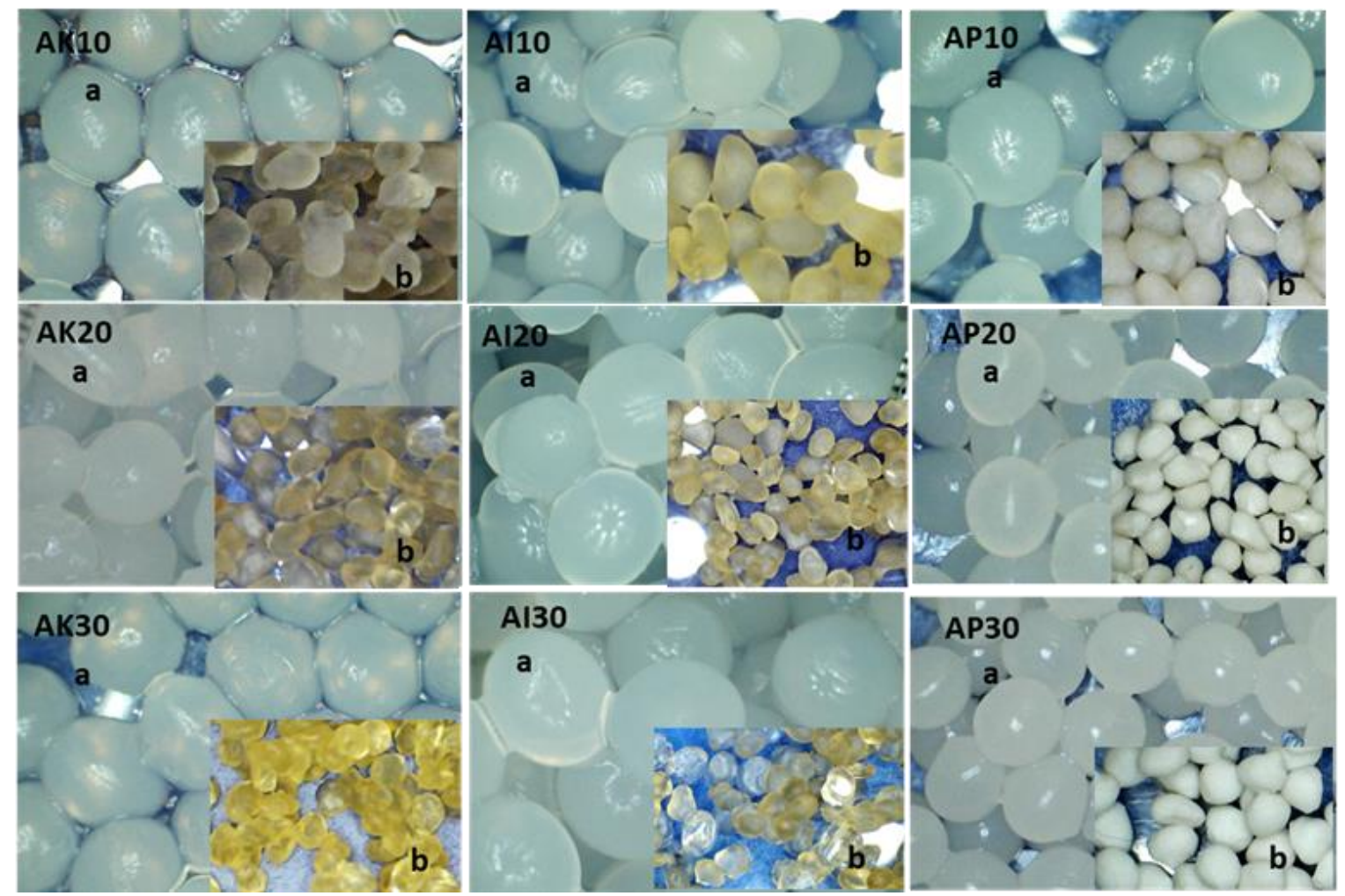

Şekil 3. Kappa kerajen ( $\kappa$-car), ioda kerajen (l-car) ve Perlit içeren hibrit taneciklerin ıslak (a) ve kuru (b) görünümleri
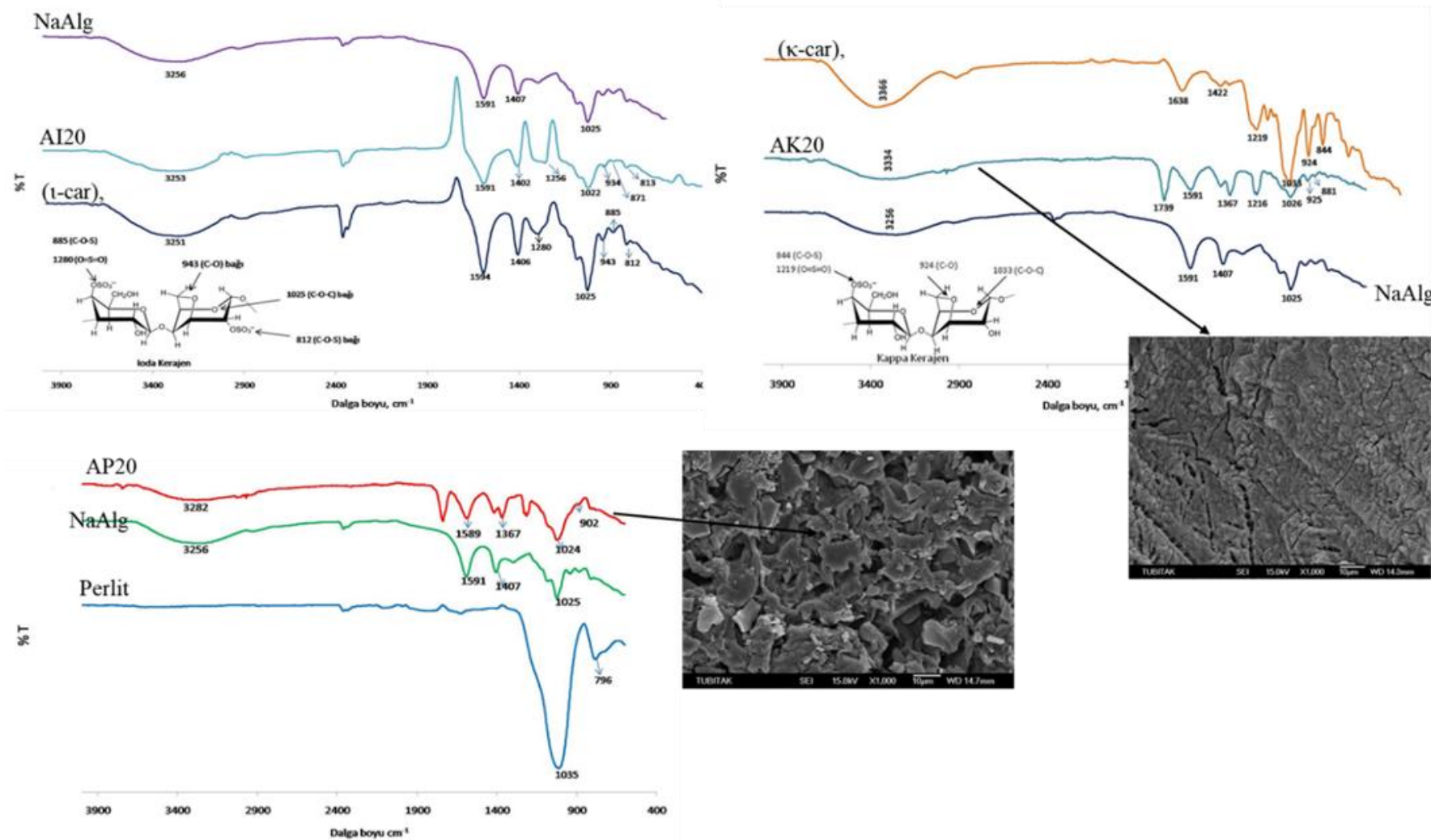

Şekil 4. Kappa kerajen (א-car), ioda kerajen ( 1 -car) ve Perlit İçeren Hibrit Taneciklerin FT-IR Spekturumları, AP20 ve AK20 Taneciklerinin Yüzey Morfolojisi 


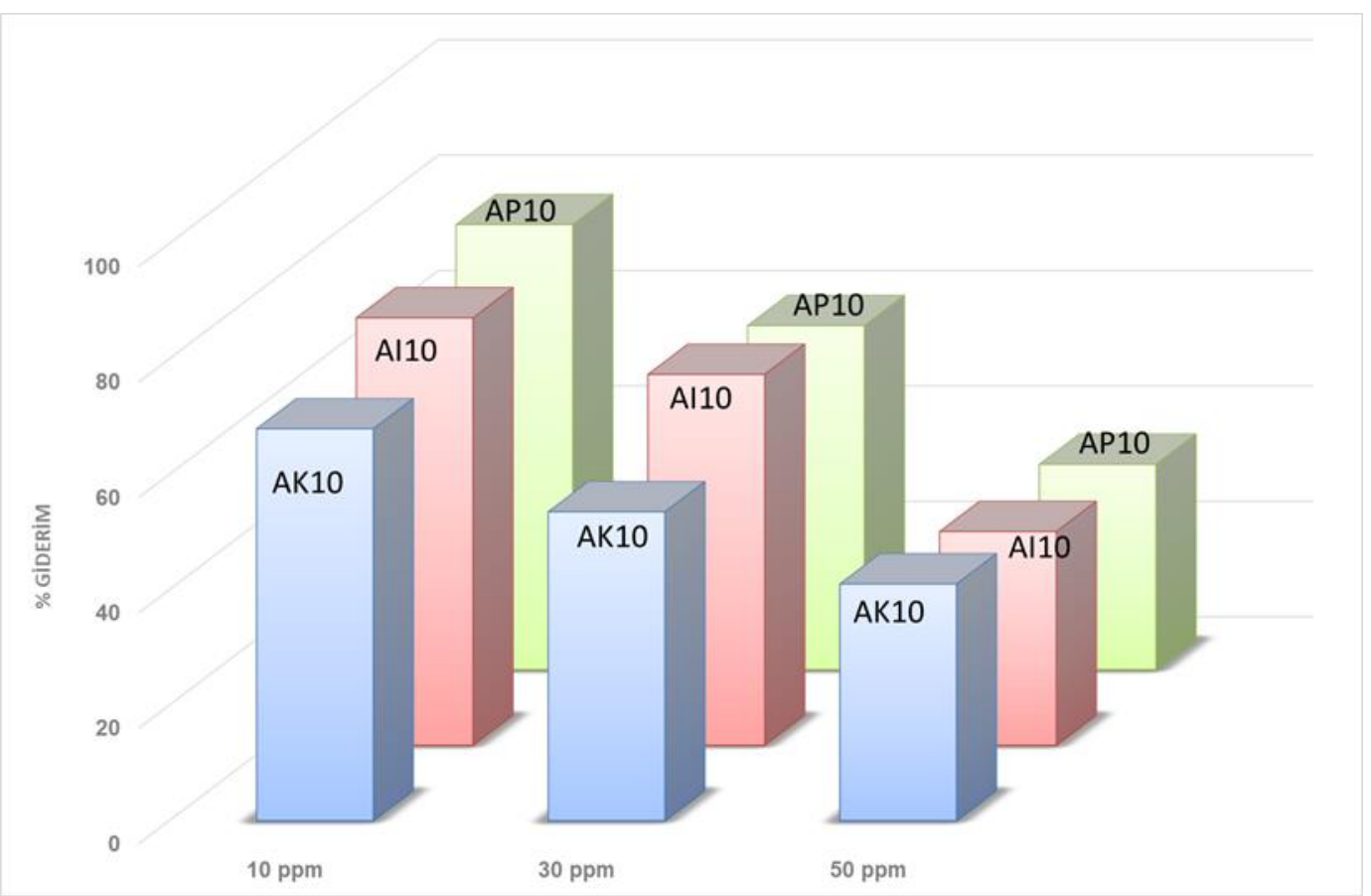

Şekil 5. Kappa Kerajen ( $\kappa$-car), İoda Kerajen ( 1 -car) ve Perlit İçeren Hibrit Taneciklerin Bakır Giderme Verimi

\section{Sonuç}

Bu çalışmada, yüksek molekül ağılıklı aljinat esas alınarak $\% 2$ sabit jel konsantrasyonunda yapisinda $\% 10, \% 20$ ve $\% 30$ oranında kappa kerajen ( $\kappa$-car), ioda kerajen ( 1 -car) ve perlit içeren küresel hibrit tanecikler hazırlanmıştır. Hazırlanan tüm hibrit taneciklerin 1slakken küreselliklerini korudukları görülmüştür. Kerajenin her iki türünün \%20 (ağ.)'e kadar yapıya girmesinin küreselliği bozmadığı, ioda kerajen (1-car) içeren AI taneciklerinin, 1slakken kappa kerajen ( $\kappa$-car) içeren AK taneciklerine kıyasla daha az küresel olduğu; ancak kuruduğunda küresel şekillerini koruyabildikleri ve kerajen türünün hazırlanan taneciğin şekil kararlılığı üzerinde çok fazla etkisi olmadığı görülmüştür. Benzer şekilde 20 (ağ.) oranına kadar hibrit tanecik yapısına katılan perlitin hibrit taneciklerin sslakken küreselliklerini bozmadığı ancak kuru halde küreselliklerini kaybetmelerine neden olduğu görülmüştür Perlitin kayaç yapısı ise kuru AP taneciklerinin küresel şeklini korumasını zorlaştırmıştır.

Kerajenin her iki türü içinde fonksiyonel grupların varlığ taneciklerin çap ve şişme derecesini etkilemiştir.

Hibrit taneciklerin potansiyel adsorban olarak kullanılabilirliği ağır metal olarak seçilen bakırın 10 ppm, 30 ppm ve $50 \mathrm{ppm}$ lik üç farklı başlangıç konsantrasyonunda bulunan sulu çözeltilerden giderimi için araştırılmıştır. AP10 tanecikleri başlangıç konsantrasyonu 10 ppm olan bakır çözeltisinden \%77,1 verimle bakırı uzaklaştırabilirken AK10 ve AI10 tanecikleri için bu verimin sırasıyla $\% 74,05$ ve $\% 67,1$ olduğu belirlenmiştir. Bu çalışmada elde edilen sonuçlar çalışma kapsamında hazırlanan küresel hibrit taneciklerin potansiyel adsorban olarak kullanılabileceklerini göstermektedir.

\section{Teşekkür}

Bu makale İrem Sarısakal'ın Yıldız Teknik Üniversitesi Fen Bilimleri Fen Bilimleri Enstitüsünde yayınlanan ve Yıldız Teknik
Üniversitesi Bilimsel Araştırma Projeleri Koordinatörlüğü'nün 2014-07-01-YL07 numaralı projesi ile desteklenen Yüksek Lisans tezi'nden faydalanarak hazırlanmıştır.

\section{Kaynakça}

Bessbousse, H., Rhlalou, T., Verchere, J.F. \& Lebrun, L. (2008). Removal of heavy metal ions from aqueous solutions by filtration with a novel complexing membrane containing poly(ethyleneimine) in a poly(vinyl alcohol) matrix. Journal of Membrane Science, 307, 249-259.

Balladares, E., Jerez, O., Parad, F., Baltierrac, L., Hernández, C., Araneda, E. \& Parra, V. (2018). Neutralization and coprecipitation of heavy metals by lime addition to effluent from acid plant in a copper smelter. Mineral Engineering, 122,112-129.

Caballero F., Foradada M., Minarro M., Pérez-Lozano P., GarcíaMontoya E., Ticó J.R. $\delta$ Suné-Negre J.M. (2014). Characterization of alginate beads loaded with ibuprofen lysine saltand optimization of the preparation method. International Journal of Pharmaceutics, 460, 181-188.

Campo, L.V., Kawano F.D., Da Silva B.D. \& Carvalho I. (2009). Carrageenans: Biological properties, chemical modifications and structural analysis - A review. Carbohydrate Polymers, $77,167-180$

Dias, A.M.G.C., Hussain, A., Marcos, A.S. \& Roque, A.C.A. (2011). A biotechnological perspective on the application of iron oxide magnetic colloids modified with polysaccharides. Biotechnology Advances, 29, 142- 155.

Ibrahim, Y., Abdulkarem, E., Naddeo V., Banat, F. \& Hasa, S.W. (2019). Synthesis of super hydrophilic cellulose-alpha zirconium phosphate ionexchange membrane via surface coating for the removal of heavy metalsfrom wastewater. Science of the Total Environment, 690,167-180. 
Fouda, M.M.G., El-Aassar, M.R., El Fawal, G.F., Hafez, E.E., Masry, S.H.D \& Abdel-Megeed, A.(2015). kCarrageenan/poly vinyl pyrollidone/polyethylene glycol/silvernanoparticles film for biomedical application. International Journal of Biological Macromolecules, 74, 179-184.

Gotoh, T., Matsushima, K. \& Kikuchi, K. (2004). Preparation of alginate-chitosan hybrid gel beads and adsorption of divalent metal ions. Chemosphere, 55, 135-140.

Klaassen, R., Ferona, P.H.M. \& Jansen, E. (2005).Membrane contactors in industrial applications, Chemical Engineering Research and Design, 83(A3), 234-246.

Keppeler S., Ellis A. \& Jacquier J.C. (2009). Cross-linked carrageenan beads for controlled release delivery systems.Carbohydrate Polymers, 78, 973-977.

Li, L., Fang Y., Vreeker R. \& Appelqvist I. (2007). Reexamining the Egg-Box Model in Calcium-Alginate Gels with X-ray Diffractio. Biomacromolecules, 8, 464-468.

Lee,K.Y. ve Mooney, D.J (2012). Alginate: properties and biomedical applications. Prog Polym Sci. 2012, 37(1), 106126.

Popa, E.G., Gomes, M.E. \& Reis, R.L. (2011). Cell delivery systems using alginate--carrageenan hydrogel beads and fibers for regenerative medicine applications. Biomacromolecules, 11, 3952-3961.

Renu B., Agarwal, M. \& Singh, K. (2017). Heavy metal removal from wastewater using various adsorbents: a review. Journal of Water Reuse and Desalination, 7(4), 387-419.
Rinaudo, M. (2008). Review: Main properties and current applications of some polysaccharides as biomaterials. Society of Chemical Industry: Polymer International, 57, 397-430.

Roulia, M.,Chassapis, K., Fotinopoulos, C.H., Savvidis, T.H. \& Katakis D. (2003).Dispersion and sorption of oil spills by emulsifier-modified expanded perlite, Spill Science \& Technology Bulletin, 8, 425-431.

Roulia M. ve Vassiliadis A. (200). Sorption characterization of a cationic dye retained by clays and perlite, Microporous and Mesoporous Materials, 116, 732-740.

Sarısakal, İ. (2017). Alginat esaslı hibrit taneciklerle ağır metal giderimi. Yıldız Teknik Üniversitesi Fen Bilimleri Enstitüsü Yüksek Lisans Tezi, 78 sayfa.

Wadhawana, S., Jaina, A., Nayyara, J. \& Mehta, S.K. (2020). Role of nanomaterials as adsorbents in heavy metal ion removal from waste water: A review. Journal of Water Process Engineering, 33, 1-17.

Yu, F., Cui, T., Yang, C., Dai, X. \& Ma J. (2019). КCarrageenan/Sodium alginate double-network hydrogel with enhanced mechanical properties, anti-swelling, and adsorption capacity. Chemosphere, 237, 124417.

Wang, J. ve Chen, C. (2009). Biosorbents for heavy metals removal and their future. Biotechnology Advances, 27, 195226.

Zang, J., Wang Q. ve Wang A. (2010). In situ generation of sodium alginate/hydroxyapatite nanocomposite beads as drug controlled release matrices. Acta Biomaterialia, 6, 445-454. 